\title{
FILOSOFÍA Y VERDAD EN LA OBRA DE RICHARD RORTY
}

\author{
Rosa Martínez González ${ }^{1}$ \\ Universidad de Zaragoza (UNIZAR) \\ https://orcid.org/ 0000-0002-2533-4897 \\ E-mail: r.martinez@unizar.es
}

\section{RESUMEN:}

En este texto se propone una lectura de la filosofía de Richard Rorty a partir de la distinción entre filosofía sistemática y filosofía edificante, proponiendo esta distinción como clave de lectura de su neo-pragmatismo y de su propuesta político-ética de los años 90, cuya consecuencia principal será su concepción de democracia liberal, de ciudadano irónico y de cultura post-filosófica

PAlABRAS ClaVE: Rorty; Filosofía sistemática; Filosofía edificante; Postmodernidad; Modernidad.

\section{PHILOSOPHY AND TRUTH IN THE WORK OF RICHARD RORTY}

\section{ABSTRACT:}

This text proposes a conception of Richard Rorty's philosophy from the distinction between systematic philosophy and edifying philosophy, proposing this distinction as a key to reading his neo-pragmatism and his political-ethical proposal of the $90 \mathrm{~s}$, whose consequence main will be his conception of liberal democracy, ironic citizen and postphilosophical culture.

KEYWORDS: Rorty; Systematic philosophy; Edifying philosophy; Post-modernity; Modernity.

\footnotetext{
${ }^{1}$ Doctor(a) en Filosofía. Profesor(a) Universidad de Zaragoza (UNIZAR), Zaragoza - España.
}

GONZÁLEZ, Rosa Martínez. Filosofía y verdad en la obra de Richard Rorty. Griot : Revista de Filosofia, Amargosa - BA, v.22 n.1, p.22-33, fevereiro, 2022. 


\section{Acerca de la sencillez de la filosofía}

En tiempos como los actuales, marcados profundamente por el hundimiento de la relación clásica que manteníamos con la verdad, es relevante volver a uno de los últimos grandes pensadores que proponían un modo diferente al clásico de habitar las regiones de lo verdadero. Richard Rorty fue uno de los últimos representantes de esta crítica a las formas clásicas de la verdad, quizás justo antes de que la posverdad empapase nuestro modo de habitar el mundo. Volver a esa antigua lucha contra la verdad puede ser relevante para entender el suelo que, actualmente, con mayor o menor fortuna, pisamos.

Pocos pensadores contemporáneos cosecharon tantos recelos como Richard Rorty. Duramente criticado por la izquierda y la derecha, por los círculos analíticos y continentales, por marxistas y liberales, por modernos y posmodernos, parece que Rorty logró, quizás a base de rechazos, hacerse con un lugar propio dentro de la reciente historia de la filosofía. Su particular pragmatismo, su voluntad de llevar a cabo una política progresista afín al liberalismo norteamericano, su asunción del relativismo cultural y epistemológico, sus ataques al platonismo, o sus ambiguas relaciones con el trabajo de autores posmodernos han contribuido a que este puesto singular que ocupa, ampliamente etiquetado como neo-pragmatismo, presente numerosos problemas y dificulte la labor de lograr una definición clara de sus posiciones políticas y filosóficas. Situado en un lugar limítrofe, casi desértico, la labor de Rorty ha importunado, durante décadas, a las primeras figuras filosóficas y políticas del momento. Habermas, Gadamer, Davidson, Foucault, Derrida, Rawls, Critchley han respondido, repudiado o criticado sus posiciones e interpretaciones.

Es por ello por lo que la tarea aquí emprendida es la de sondear su trabajo y analizar sus líneas maestras para poder así proponer una invitación a Rorty. Una invitación a prestar oído a su pensamiento, asumiendo que prestar oído nunca debe ser una labor de recepción acrítica, sino que, al contrario, prestar oído implica una capacidad para percibir y distinguir, es decir, un modo particular-filosófico- de atención.

Al enfrentarse por vez primera con la obra de Richard Rorty, lo primero que nos llama la atención es la aparente facilidad y desenvoltura de su prosa, su estilo atractivo e irónico, su modo de deshacerse, con una sencillez pasmosa, de los grandes problemas que lastran la filosofía occidental desde hace siglos. La obra de Rorty se nos presenta, en primer lugar y ante todo, como una lectura ligera. De escritura fácil y expresión directa, los problemas filosóficos van desfilando a lo largo de las páginas dando la impresión de que han sido traducidos o librados de unas cargas innecesarias mostrándose, ahora, en su pura neutralidad. Y, paradójicamente, esta aparente sencillez, esta aparente neutralidad que no sólo implica a los problemas filosóficos, sino a la filosofía entera de Rorty, es la complejidad a la que debemos atender. La complejidad que encierra la filosofía de Rorty proviene de la sencillez con la que es presentada, porque esta sencillez no es tan sólo una cuestión de estilo, sino que, como veremos, es expresión de toda una concepción filosófica que puede ser definida como filosofía edificante o ironismo.

Quizás el mejor acercamiento a su apuesta por la sencillez filosófica se pueda encontrar en su primer gran libro, La filosofía como espejo de la naturaleza. Un libro osado que supone el definitivo alejamiento de Rorty con respecto a la filosofía analítica. Dicho alejamiento es una cuestión crucial a la hora de proponer un modo particular y propio de sencillez filosófica, pues la apuesta analítica, desde sus primeras formulaciones, identificó la complejidad filosófica como una problemática estéril derivada de errores lógicos en la formulación filosófica. La filosofía analítica tradicional proponía una sencillez filosófica que pasara por una reducción a pura lógica de las grandes proposiciones filosóficas y metafísicas. A través de esta reducción y de una correcta 
utilización del lenguaje, el sueño analítico preveía la eliminación de toda complejidad y la consecución de una particular sencillez filosófica. Sin embargo, la propuesta de Rorty es diametralmente opuesta. Conviene con la filosofía analítica que los grandes problemas filosóficos y las elucubraciones metafísicas tradicionales no son sino fruto de un equívoco. Pero no se trata de un equivoco lógico. El gran error de la filosofía nada tiene que ver con la correcta formulación de las proposiciones, sino con una idea errónea larvada en el pensamiento de los filósofos que todavía hoy perdura. Esta idea errónea, inaugurada por Dercartes y continuada por la filosofía moderna es, para Rorty, la idea de mente, de la cual participa incluso la misma filosofía analítica.

De un modo semejante a la censura heideggeriana de la metafísica tradicional y a la denuncia foucaultiana del conocimiento de sí, Rorty sitúa la deriva errónea de la historia de la filosofía en el privilegio de un concepto por parte de un autor - Descartes- que influye de un modo determinante en la construcción filosófica de la modernidad, de tal modo que dicha construcción perpetúa un error fundacional - la mente- que provoca el extravío. Rorty marca un punto de inflexión clave en la filosofía moderna, un camino de no retorno, justamente, en la filosofía cartesiana. Descartes, pues, como emblema tanto de la filosofía moderna como de sus sombras y extravíos. Y dichos extravíos provienen de la inauguración de un nuevo modo de hacer filosofía basada en la metáfora de la mente como espejo de la naturaleza. O, dicho de otro modo: los problemas filosóficos provienen de la pretensión de conocer los fundamentos del conocimiento mediante métodos puros, puramente mentales. En tanto la mente contiene representaciones, es posible estudiar con métodos racionales los fundamentos de verdad de dichas representaciones, con lo que el acceso a la verdad no depende de ningún modelo empírico, sino de un modelo puro, racional, convirtiendo el acceso a la verdad en una cuestión procedimental y, a la vez, en fundamento mismo de la filosofía. Tal es, según Rorty, el nacimiento de la epistemología que, a partir de la idea de mente cartesiana se va a desarrollar con Locke y encontrará su punto culminante en las categorías kantianas. Es un lugar común la consideración de que a partir de Descartes comienza la filosofía, mediante la búsqueda racional de certezas, a distanciarse de la religión y a lograr un campo propio de reflexión que podrá, posteriormente, ser denominado epistemología o teoría del conocimiento. Sin embargo, el giro de Rorty es más osado (DEWEY, 1952, p.21). Hace depender los problemas de la filosofía tradicional de la invención misma de la epistemología, presa en la imagen del espejo de la naturaleza, de la teoría de la representación: 'la historia de la filosofía moderna es la historia de la consolidación de esta desafortunada autoimagen' (CALDER, 2005, p.2). El extravío de la filosofía moderna pasa a depender de su mismo nacimiento, con lo cual Rorty se desmarca de toda la filosofía analítica al trasladar al nacimiento mismo de la filosofía moderna su deriva. Descartes con la habilitación de su cogito, recupera la idea platónica de las verdades ideales - verdades que son ciertas debido a sus causas en lugar de a sus argumentos-, con una diferencia: traslada al terreno epistemológico lo que, en Platón, correspondía al terreno metafísico. Esta diferencia, se basa en la invención de un nuevo ámbito interior - la mente-(RORTY, 1983, p.53) en dónde se va a jugar la necesidad de las verdades según el criterio de certeza, criterio que nos dará la seguridad de que el conocimiento de los objetos internos, las representaciones, es más seguro y cierto que el de los objetos externos.

La invención de la mente hecha por Descartes [...] dio a la filosofía nueva base en la que apoyarse. Ofreció un campo de investigación que parecía previo a los temas sobre que se habían manifestado los antiguos filósofos. Además, proporcionaba un ámbito dentro del cual era posible la certeza, en oposición a la mera opinión (RORTY, 1983, p.132).

El cambio que supuso Descartes, fue, de este modo, insólito. Cambia el suelo de la filosofía, la consideración de sus fundamentos, se habilita un espacio nuevo, interior, llamado mente, que posee la facultad de contener representaciones que son juzgadas de acuerdo con un criterio

GONZÁLEZ, Rosa Martínez. Filosofía y verdad en la obra de Richard Rorty. Griot : Revista de Filosofia, Amargosa - BA, v.22 n.1, p.22-33, fevereiro, 2022. 
puramente epistemológico. Se abandona la búsqueda de la sabiduría, se desvincula la filosofía de la vida, y el pensamiento se vuelva hacia la definición de esos fundamentos del conocimiento que constituyen no sólo nuestra interioridad, sino la clave misma del saber. Éste es el espacio abierto por Descartes: la mente, la posibilidad de cambiar sabiduría por epistemología. Y, precisamente, la crítica de Rorty consiste en denunciar las pretensiones de dicha epistemología, el corazón mismo de la filosofía moderna.

Contra la idea de mente, contra la epistemología, contra el error filosófico del cual participa la modernidad casi en su totalidad, Rorty propone un modo diferente de hacer filosofía. Una filosofía que repare su error inaugural y que descrea de todo fundamento epistemológico fuerte. Para ello, Rorty pretende acabar con la epistemología, con el conocimiento como objeto de una teoría, con toda idea de fundamento, con el representacionismo y con la filosofía tradicional: 'El objetivo de esta obra es acabar con la confianza que el lector pueda tener en la mente, [...] en el conocimiento en cuanto algo que debe ser objeto de una teoría y que tiene fundamentos, y en la filosofía tal y como se viene entendiendo desde Kant' (RORTY, 1983, p.16). Es así como la sencillez filosófica rortyana no es una mera cuestión de estilo, sino una cuestión compleja que nos lleva hacia el intento de romper con la filosofía tal y como se viene entendiendo hasta ahora, emplazándonos ante la posibilidad de pensar de otro modo, de realizar una filosofía edificante.

Frente a la filosofía tradicional y sus seguridades epistemológicas, la filosofía edificante se hace fuerte en la duda, en la sospecha, en la desconfianza. Desconfianza hacia la epistemología, pues las fuentes del conocimiento no son más que expresión de nuestros propios errores de juicio. Desconfianza hacia las esencias, pues quizás no sean más que monedas gastadas, troqueladas, impuestas como absoluto. Y desconfianza hacia el progreso y la universalidad, que quizás no sean más que ficciones teóricas, sueños de una razón bárbara. Esta filosofía edificante, profundamente escéptica e irreverente, crece en los márgenes de la filosofía sistemática. Los filósofos edificantes se niegan a ofrecer representaciones exactas de las cosas, consideran que ésa no es la forma adecuada del pensamiento, están convencidos de que 'quizás el decir cosas no sea siempre decir cómo son las cosas' (RORTY, 1983, p.335), y en esa convicción inserta Rorty su labor. De este modo, Rorty anticipa el final de la filosofía como espejo de la naturaleza, la disolución de la filosofía como disciplina privilegiada para el acceso a la verdad, el abandono de la figura del filósofo como aquel que posee un conocimiento más válido que el resto.

Si la filosofía tradicional se caracterizaba por intentar justificar verdades por argumentos, Rorty afirma que la filosofía edificante aspira a mantener una conversación, pues la interrupción de la conversación sólo podría ocurrir por medio de la imposición de una verdad. De este modo Rorty colige de la crítica a la verdad tradicional la necesidad de fomentar una discusión dirigida al provecho de la humanidad. Edificante, pues, porque no ofrece sistemas, verdades, universales o fundamentos, sino porque contribuye a la edificación de la humanidad mediante la conversación. Precisamente, la negativa de la filosofía edificante a introducirse en el discurso normal, a institucionalizarse, le sirve a Rorty para soldar el carácter de conversación permanente a la filosofía edificante y declarar la disolución de la filosofía tradicioinal. Así, el final de $L a$ filosofía y el espejo de la naturaleza se cierra con toda una declaración de intenciones: "Lo único en que yo quisiera insistir es en que el interés moral del filósofo ha de ser que se mantenga la conversación del occidente, más que el exigir un lugar, dentro de esa conversación, para los problemas tradicionales de la filosofía moderna" (RORTY, 1983, p.335).

Con ello, la filosofía edificante que late en el corazón de la tarea rortyana es, al mismo tiempo, la cifra de su sencillez y de su complejidad. Filosofía edificante o irónica que proclama la disolución de la filosofía tradicional y que abre un espacio que, en este texto, desgranaremos en tres epígrafes. Epígrafes que no pretenden agotar las lecturas de su obra, sino tan sólo invitar a su 
pensamiento, constituir una vía de entrada que nos ofrezca las principales marcas y los principales problemas a los cuales atender con vistas a adentrarnos en su obra.

\section{Renunciar a la complejidad filosófica}

Parece evidente que la pretendida sencillez de la filosofía edificante que plantea Rorty choca frontalmente con la seriedad que se le atribuye al trabajo filosófico. Precisamente, esta seriedad filosófica, identificada por Rorty como filosofía de raíz platónica, es una de las principales tradiciones contra las que se levanta la filosofía edificante. Los filósofos excesivamente serios son aquellos que se esfuerzan por mantener principios metafísicos, epistemológicos u ontológicos que gobiernen el edificio de su sistema filosófico. Rorty identifica este tipo de trabajo filosófico, que denomina filosofía tradicional, con aquellas reflexiones que han marcado el espacio de la modernidad. No sólo Platón, sino Descartes, Kant y Hegel y toda aquella filosofía que pretenda garantizar un acceso a la verdad del hombre, del mundo o de Dios. Renunciando a los trascendentales, a la voluntad de verdad y a la seguridad epistemológica, la filosofía edificante de Rorty trata de huir del gran error cartesiano (la mente como espejo de la naturaleza) y del error metafísico platónico (identificación entre conocimiento y virtud), a través de la definición de la filosofía como conversación infinita. En su particular cruzada contra los filósofos excesivamente serios, Rorty introduce una partición que pretende cortocircuitar la posibilidad de establecer un fundamento filosófico que reproduzca los errores de la metafísica y la epistemología. Dicha partición es la diferenciación entre el ámbito público y lo privado. El lugar donde Rorty expone más claramente la división, sus motivos y sus consecuencias, es Contingencia, ironía y Solidaridad, obra que, a través del reconocimiento de la contingencia, propone la radical separación entre lo público y privado renunciando a la unión metafísica entre realidad y justicia: "Decidí, entonces, escribir un libro sobre cómo sería la vida intelectual si uno consiguiera abandonar el intento platónico de mantener la realidad y la justicia en una imagen única" (RORTY, 1992, p.38).

Contra la idea de un fundamento, contra la pretensión del filósofo serio consistente en intentar aprehender la realidad a través de un sistema categorial, Rorty introduce la contingencia como raíz misma de toda ontología. Para Rorty las grandes categorías filosóficas -yo, mundo y lenguaje- no son sino expresión de la contingencia absoluta y de la inconmensurabilidad entre pensamiento y realidad. Para lograr que los filósofos excesivamente serios respeten el abismo entre realidad y pensamiento y abandonen la pretensión de conducir al mundo hacia una dirección pretendidamente verdadera -y generalmente desastrosa-, Rorty introduce la división entre lo público y lo privado que actúa como una suerte de vacuna contra las tentaciones absolutistas del pensamiento. Se permite que los filósofos excesivamente serios sigan siendo serios, pero en un territorio estrictamente privado. Sus seguridades, sus dioses propios, sus palabras sagradas pertenecen a la región que Rorty identifica con la metáfora de las orquídeas salvajes, es decir, a una región privada que nunca debe convertirse en territorio común ya que varía con cada individuo. Con el objetivo de garantizar la diversidad del pensamiento, Rorty establece que la filosofía edificante debe asegurar el hecho de que ciertas orquídeas individuales no aplasten al resto convirtiéndose en verdades comunes. Es por ello que, mientras el territorio privado puede estar poblado de dioses y demonios cualesquiera, el ámbito público debe permanecer abierto constantemente, y no se debe admitir ningún intento de invasión del espacio público desde el espacio privado, ya sea con ideas religiosas, morales o políticas. Esto supone sustituir el principio de objetividad que tradicionalmente reinaba en el espacio público por el principio de solidaridad, del tal modo que la conversación que permita configurar el espacio público sea una conversación basada únicamente en la solidaridad y el principio de no crueldad, más allá de los valores propios y las convicciones personales que forjan los caracteres individuales.

GONZÁLEZ, Rosa Martínez. Filosofía y verdad en la obra de Richard Rorty. Griot : Revista de Filosofia, Amargosa - BA, v.22 n.1, p.22-33, fevereiro, 2022. 
El espacio privado rortyano es el terreno de la contingencia, de la indeterminación, del juego de intereses individuales y egoístas, de la estetización de la existencia, de la creación de sí, de la ironía (RORTY, 1994, p.92). Las orquídeas salvajes de cada uno, las flores del mal propias, las convicciones religiosas o políticas, nada tienen que hacer en un territorio común y público y por ello deben desaparecer del mismo. El espacio público desde deshacerse de cualquier principio trascendental y, asumiendo la contingencia, tratar de vertebrar una comunidad contingente que permanece unida a través de un léxico común y cambiante, de una colección de metáforas comunes que permiten la supervivencia de las orquídeas individuales y fomentan la solidaridad y la no crueldad. Sin embargo, para Rorty la filosofía excesivamente seria carece de la capacidad irónica de asumir su propia contingencia. El requisito fundamental para formar parte de la comunidad contingente rortyana es la asunción de la ironía, es decir, el asumir que todo los valores propios, incluso las creencias más hondas, son fruto de la contingencia y pueden ser revisados, redescritos. La ironía nos emplaza ante el hecho de que las verdades son metáforas muertas, que dependen de un uso determinado, de un contexto determinado. La ironía, en lugar de proveernos de argumentos, de razones o de seguridades, nos priva de ellas. Nos enfrenta a la absoluta contingencia de quien no puede, ni siquiera, justificar su vocabulario último (RORTY, 1994, p.91). Tal requisito, afirma Rorty, no es cumplido por gran parte de la filosofía excesivamente seria, pues intenta constantemente interferir en el espacio público e imponer sus valores propios. La solución de Rorty es clara y radical. La filosofía que contenga residuos de esta seriedad debe, no sólo ser reintegrada en la esfera de lo privado, sino desaparecer. Rorty será lapidario con la filosofía tradicional. La filosofía tradicional, al contener pretensiones políticas, al albergar la aspiración irrenunciable de lo público, al pretender un vínculo entre ideas fuertes de razón, historia y política, supone un peligro constante para la necesaria división entre lo público y lo privado. Un peligro que se fundamenta en un error, en una ilusión, en sueños de visionarios. Es por ello por lo que la filosofía debe ser expulsada de lo público. O dicho de otro modo, la filosofía debe aceptar la deserción de la política y asumir su nuevo lugar en una cultura post-filosófica.

Para contribuir a poner en su lugar a los filósofos excesivamente serios, Rorty utiliza la filosofía de corte nietzscheano -Nietzsche, Heidegger, Derrida, Foucault-, su paciente deconstrucción no sólo de las categorías epistemológicas tradicionales, sino de las pretensiones políticas, las falsas inocencias, las mil máscaras con las que la razón ilustrada introducía elementos perniciosos. Sus críticas a la metafísica y la epistemología poseen unas claras connotaciones postnietzscheanas y parece, en un principio, que Rorty puede ser asignado a esa tradición que bebe de la tarea inaugurada por Nietzsche y que posee su ethos primordial en el derribo de ídolos, dioses y valores. Ahora bien, ¿es capaz la filosofía post-nietzscheana de aceptar las divisiones y marcas con las cuales Rorty demarca el territorio de la filosofía? Para abandonar a los filósofos excesivamente serios y asumir una cultura post-filosófica, ¿debemos aceptar el ethos de los filósofos excesivamente joviales?

\section{Contra filósofos excesivamente joviales}

La obra de Rorty está plagada de referencias a la tradición nietzscheana. El mismo Rorty se nos presenta, numerosas veces, como un hábil defensor de las posturas post-nietzscheanas (RORTY, 1992b). Es patente la seducción que Rorty ejerce entre los lectores que pertenecen a una audiencia próxima al post-nietzscheanismo. Se encuentran en sus páginas brillantes argumentos a la hora de afianzar sus posiciones con respecto a la filosofía tradicional (RORTY, 1983, p.334). La filosofía excesivamente jovial provee a Rorty de elementos valiosísimos a la hora de realizar la crítica a la filosofía excesivamente seria. En un escenario filosófico - el continental-

GONZÁLEZ, Rosa Martínez. Filosofía y verdad en la obra de Richard Rorty. Griot : Revista de Filosofia, Amargosa - BA, v.22 n.1, p.22-33, fevereiro, 2022. 
marcado por la división entre modernidad y postmodernidad, la posición de Rorty parece decantarse por esta última. El motivo principal es que, según Rorty, el establecimiento de fundamentos supone la imposibilidad de utilizar la filosofía tradicional para fomentar la contingencia y la solidaridad. En cambio, la filosofía post-nietzscheana, aunque pueda presentar problemas, es una valiosa aliada en este sentido. Permite, quizás de modo más lapidario que ninguna otra tradición, atacar la noción de fundamento y de unidad, abriendo la posibilidad a la asunción de la contingencia en el terreno lingüístico, antropológico y epistemológico. Pero, pese a ser una buena aliada en la prédica de la contingencia, los filósofos excesivamente joviales le presentan a Rorty un buen número de problemas.

Sus problemas son de orden político: la filosofía post-nietzscheana supone un salto de lo filosófico a lo político basado en la auto-creación privada. Y éste es el principal motivo por el cual Rorty rechaza que la filosofía excesivamente jovial pueda ser un modelo válido para el espacio público que trata de diseñar con su filosofía irónica. Porque, en su exceso de jovialidad, la filosofía post-nietzscheana es incapaz de distinguir entre el papel de ciudadano (público) y el papel de autocreación personal (privado). Si los filósofos excesivamente serios son desestimados debido a su falta de ironía y de auto-invención, los filósofos excesivamente joviales lo son debido a su exceso de ironía y auto-invención. Ambas figuras filosóficas sobrepasan la demarcación entre lo público y lo político. La tradicional, intentando hacer de lo público una región arquitectónica y fundamentada. La post-nietzscheana, introduciendo la ironía y la contingencia en lo público, impidiendo así, según Rorty, la construcción de una comunidad. A este respecto, y hablando de Foucault, Rorty expresa claramente su negativa a que las teorías de los filósofos excesivamente joviales formen parte de su filosofía edificante e irónica:

\footnotetext{
Yo hubiera deseado que Foucault se inclinara más a distinguir estos dos papeles, a distinguir su identidad moral de ciudadano y su búsqueda de autonomía personal. Entonces habría podido resistir la tentación a la que sucumbieron Nietzsche y Heidegger: la tentación de buscar en su propia esfera privada una contrapartida pública y política. Fue esa tentación la que provocó su casi anarquismo y su negativa a ser cómplice del poder (RORTY, 1994, p.326)
}

Encontramos dos motivos principales por los que los filósofos excesivamente joviales serán excluidos de esta nueva comunidad rortyana. El primero, el sentido de la crítica que poseen autores inspirados en la genealogía nietzscheana. El segundo, el sentido de la ironía de autores cercanos al post-nietzscheanismo. En cuanto al primer problema, el carácter de la crítica que emana del concepto genealógico nietzscheano mantiene un último vínculo con la ontología que no permite el pleno reconocimiento de la contingencia. Un genealogista, al buscar la invención de las verdades, no hallará tan sólo azar, sino una batalla de fuerzas con vencedores y vencidos. La verdad nunca será inocente y, por lo tanto, un mundo y una cultura construidos sobre tales verdades siempre serán sospechosos. La sospecha como fuente de la crítica es lo que impide a la filosofía post-nietzscheana de filiación genealógica aceptar la contingencia del mundo que nos rodea. Y, precisamente, un análisis del presente que indague en las condiciones de posibilidad del mundo que nos rodea es lo que contraviene la definición de una cultura post-filosófica como la rortyana. Para Rorty, como veremos, el lugar de la filosofía no es el de la crítica social, pues ésta requiere ciertos fundamentos de raíz ontológica incompatibles con el pleno reconocimiento de la contingencia.

Por otro lado, el carácter post-nietzscheano de la ironía presenta dificultades a la hora de conciliarse con la idea rortyana de ironía. Para Rorty un individuo irónico es aquel que duda de su vocabulario último y por ello se permite la tarea de una constante redescripción personal a la medida de sus propios sueños, teniendo en cuenta que la medida de sus sueños es la medida de su 
espacio privado. La ironía, en tanto auto-creación individual, poética, estetizante, no puede rebasar los límites del espacio privado. El espacio público debe garantizar y fomentar la ironía individual, pero precisa un suelo común, un vocabulario compartido en el que no exista la ironía pública, sino redescripciones orientadas a convencer a la comunidad sobre la adopción de una nueva verdad que resulta más útil a la constitución de ese nosotros.

La filosofía que, de algún modo, continúa la tarea nietzscheana no se detiene en la ironía privada, sino que continua hasta la ironía pública. Lo público está sometido a la contingencia al igual que lo privado, se encuentra abierto a la eterna redescripción, a la risa, a la ironía. Así, el problema de la posición de Rorty se nos aparece al concebir la posibilidad, reclamada por numerosos pensadores postnietzscheanos (Foucault, Derrida, incluso el propio Nietzsche), de someter al espacio público a la misma crítica irónica que se realiza con el privado; desvelando así su contingencia, sometiéndolo a redescripciones sucesivas del pasado con el objetivo de practicar una creación de futuro. Descreer tanto del vocabulario íntimo como del vocabulario de la comunidad, introduciendo la mirada de la sospecha en las construcciones públicas. En este sentido se expresa S.Critchley a la hora de criticar el radical rechazo rortyano a la ironía nietzscheana:

Rorty rechaza el rico potencial de considerar ironistas públicos a pensadores como Nietzsche y Foucault, críticos, tanto de las formaciones políticas y sociales democráticoliberales que privatizan la autonomía, como del resbaladizo declive que permite que la afirmación de la contingencia del yo se deslice hacia un disciplinamiento conductista [...] del sujeto (CRITCHLEY, 2002, p.56)

En definitiva, el problema que el post-nietzscheanismo le supone a Rorty no es otro que el problema político. El problema derivado de una filosofía que, en su exceso de jovialidad, pretende extrapolar esa jovialidad como máxima universal proponiendo una crítica y una ironía públicas de fuertes connotaciones políticas. Y, sin embargo, Rorty asume que el post-nietzscheanismo es la mejor opción no sólo para defender la filosofía edificante, sino para defender a la comunidad liberal. Es posible, según Rorty, utilizar el potencial desmitificador de filósofos como Foucault, Derrida o Heidegger y anular los problemas que suscitan integrando su potencial autocreador y crítico en lo privado. Efectivamente, sus acercamientos al post-nietzscheanismo, sus comentarios sobre Nietzsche, Heidegger o Foucault, van en esta dirección: intentar convencer a la audiencia post-nietzscheana de que es en lo privado en dónde puede y debe, con total libertad, asumir su papel de filosofía irónica y promover la creación de sí como perfeccionamiento individual a través de los sueños de autonomía:

La función crítica, utópica, de Contingencia, Ironía y Solidaridad es persuadir a los metafísicos liberales de que se conviertan en ironistas $[. .$.$] y a los ironistas de que se$ conviertan en liberales. Es importante señalar que Rorty cree que esta persuasión no tendrá lugar a través de la argumentación (como en la filosofía) [...] Contingencia, Ironía y Solidaridad no pertenece, por lo tanto, al género de la filosofía, sino más bien al de la crítica literaria que, para Rorty, es la única forma de discurso que puede tener relevancia moral en nuestra cultura posfilosófica (CRITCHLEY, 2002, p.52-53)

Se trata de un intento de persuasión orientado contra un enemigo que se nos muestra como un enemigo filosófico y político en la medida en que la filosofía post-nietzscheana abandera la cuestión de la crítica y la política como substanciales a la tarea del pensar. Así, la persuasión rortyana va encaminada a absorber la crítica filosófica del post-nietzscheanismo, orientarla hacia la autocreación en lo privado y privarla de toda connotación política. Convencer, en una palabra, a la audiencia post-nietzscheana de que, en lugar de arrojar sospechas sobre lo público, debe dedicarse a la creación de sí en lo privado y participar como ciudadanos en una comunidad liberal

GONZÁLEZ, Rosa Martínez. Filosofía y verdad en la obra de Richard Rorty. Griot : Revista de Filosofia, Amargosa - BA, v.22 n.1, p.22-33, fevereiro, 2022. 
es la mejor opción - la única- en una cultura post-filosófica. Esta persuasión forma parte del modo en que la filosofía edificante establece un nosotros cada vez más amplio, una comunidad inclusiva que permita el ideal de la conversación infinita y nos acerque, cada vez más, al modelo de utopía liberal que Rorty plantea.

Así, hemos visto de qué modo Rorty pretende fundar un espacio que acabe con los grandes errores de la filosofía. Su sencillez filosófica nos ha llevado hasta la asunción de la ironía y la contingencia y la exclusión de toda filosofía excesivamente seria o excesivamente jovial que no respete los límites de lo público y lo privado. De este modo, el espacio que propone Rorty, el de la filosofía edificante o irónica, es el espacio de una cultura post-filosófica. Es decir, una cultura refractaria a todo intento de fundamentar o criticar el mundo en que vivimos. Una cultura de la conversación y solidaridad orientada a cimentar los principios políticos del liberalismo. La tarea de Rorty se quiere situar más allá de la filosofía. Concretamente, la tarea rortyana consiste en expulsar a la filosofía y a la política de la comunidad, creando una cultura post-filosófica que será el nuevo territorio sobre el cual Rorty pretende ayudar a construir una nueva ciudad. La filosofía, desde el sueño del filósofo rey, había pretendido fundar la ciudad sobre las bases del conocimiento y la virtud. Éste había sido su gran sueño político, utópico. Sin embargo, la utopía rortyana comienza con el abandono de la filosofía y nos presenta una extraña y, sin embargo, familiar ciudad. La ciudad irónica como símbolo de la utopía liberal rortyana.

\section{Filosofía y posverdad}

La respuesta de Rorty a los filósofos excesivamente serios y a los excesivamente joviales es clara. Los filósofos demasiado serios quedan excluidos de la ciudad irónica porque carecen de la contingencia requerida para convertirse en modelo privado o público. En cambio, los filósofos demasiado joviales son requeridos para el territorio privado y expulsado del ámbito público. En la cultura post-filosófica que plantea Rorty, el lugar de la filosofía es el de la sumisión a la democracia. A este respecto, es paradigmática la posición que mantiene Rorty con respecto a dos filósofos, Habermas y Foucault, símbolos contemporáneos de la tradición seria y de la tradición jovial:

Para indiciar las diferencias crudamente: Foucault es un ironista que no está dispuesto a ser liberal, mientras que Habermas es un liberal que no está dispuesto a ser un ironista [...] Mientras que mis diferencias con Foucault son políticas, mis diferencias con Habermas son lo que a menudo se denomina diferencias meramente filosóficas (RORTY, 1984, p.82-83)

Pese a que los filósofos serios sean capaces, según Rorty, de mantener una posición política correcta -liberal-, su filosofía está completamente errada y en nada puede ayudar al avance del liberalismo. Es por ello que la filosofía seria debe ser desestimada. Y, del mismo modo, pese a que los filósofos joviales acierten en el terreno filosófico, sus ambiciones públicas les llevan hacia posiciones políticas equivocadas. Es por ello que la tarea principal de la labor rortyana será establecer el lugar que debe ocupar la filosofía en el seno de una cultura post-filosófica y liberal. Una cultura en la que ya es obvio que la posición política liberal posee preeminencia con respecto a cualquier posición filosófica. Si en otras épocas la filosofía era una llamada a construir una ciudad y ponerla en orden a partir de determinados ideales - justicia, igualdad, humanidad-para Rorty es la ciudad la que debe llamar al orden a la filosofía y mostrarle su espacio y su papel. No es la filosofía liberal la que construye la ciudad liberal, sino que es la ciudad liberal la que construye el espacio filosófico pertinente y útil a sus intereses. Ésta es, quizás, la piedra de toque del trabajo rortyano. Su método pragmatista no es sino la obediencia a la ciudad, la conversión

GONZÁLEZ, Rosa Martínez. Filosofía y verdad en la obra de Richard Rorty. Griot : Revista de Filosofia, Amargosa - BA, v.22 n.1, p.22-33, fevereiro, 2022. 
de la filosofía a la utilidad liberal, la deserción de la filosofía. Y ni la filosofía seria ni la filosofía jovial cumplen plenamente estas prerrogativas. Michel Foucault, paradigma de la filosofía jovial, es un ironista que no está dispuesto a ser liberal, y Jürgen Habermas, filósofo serio, es un liberal que no está dispuesto a ser ironista. Así pues, ¿̨cuál es exactamente el lugar de la filosofía en la ciudad rortyana? En su artículo La prioridad de la democracia sobre la filosofía, Rorty deja claro el lugar asignado a la filosofía en su ciudad irónica:

La verdad [...] es irrelevante para la democracia política. Y por lo mismo también lo es la filosofía, como explicación de las relaciones existentes entre un orden dado y la naturaleza humana. Cuando entran en conflicto, la democracia tiene prioridad sobre la filosofía (RORTY, 1992, p.261)

Con ello, para Rorty la filosofía debe mantener una relación de sumisión con respecto al ideal político de la democracia liberal norteamericana, convirtiéndose en una tarea exclusivamente privada orientada a fomentar la contingencia de los propios valores a través del derribo de los ídolos modernos y el establecimiento de una ética humanitarista que fomente individuos contingentes y liberales. De ahí que la función de la filosofía cambie por completo en la ciudad rortyana y se identifique con la función que, tradicionalmente, se reservaba a la literatura, esto es, la auto-creación. Si tradicionalmente se había reservado a la literatura el marco de la perfección de sí y a la filosofía el marco en el cual se debía teorizar y fundamentar la convivencia pública, en la cultura irónica y post-filosófica rortyana los términos se invierten. Es la filosofía la que queda ligada esta tarea de perfección privada, a la creación de sí. Y es la literatura la que posee las competencias necesarias para el fomento de la solidaridad. En el ámbito ético privado prima la filosofía como medio de conseguir la perfección privada: "la teoría se ha transformado en un medio al servicio de la perfección privada y no al servicio de la solidaridad humana" (RORTY, 1992, p.115). Sumidos en una cultura post-filosófica, la filosofía no tiene otra tarea que la deriva ética de la perfección de sí. Y, del mismo modo, la filosofía de nada puede servir a desarrollos éticos públicos, pues éstos deben estar basados en el tejido del sentimiento. Será, entonces, la literatura la que nos provea de los elementos adecuados para fomentar el sentimiento público de solidaridad. De hecho, Rorty acude frecuentemente a los ejemplos de Nietzsche, Heidegger y Derrida como modos de contribuir a la perfección ética privada, pese a que tales intentos fracasaran debido a la indeterminación de las fronteras entre lo público y lo privado. Y sitúa a escritores como Nabokov o Dickens como ejemplos de fomento de propuestas éticas públicas. En la cultura post-filosófica la filosofía queda reducida a una tarea de autocreación de sí y la literatura se revela como un modo de ética pública postmoralista basada en la solidaridad y el sentimiento.

De este modo, la tarea de esta filosofía puesta al servicio de la democracia liberal queda expresada en dos líneas principales: fomentar la contingencia y, paralelamente, procurar la autocreación del individuo, aquello que Rorty llama creación de sí, circunscribiéndola al ámbito privado. En otras palabras, la tarea de la filosofía será la deconstrucción del individuo tradicional y su conversión en individuo irónico. Para ello, la filosofía edificante o irónica propia de la ciudad liberal desarmará las íntimas coherencias del individuo que la filosofía posmoderna había dejado intactas - la formación de una interioridad soberana- e introducirá las prerrogativas necesarias para que la ciudad irónica sea capaz de establecer un modelo disciplinario conductista de acuerdo con la economía de mercado liberal. Para Rorty, la tarea de la filosofía no es otra que la de producir individuos liberales íntima y éticamente unidos a la economía de mercado (Lipovestky, 1994). El individuo irónico que debe predicar la filosofía en la ciudad rortyana es un individuo carente de centro, que está formado por una sucesión de fragmentos sometidos a la contingencia. De ese modo, sus deseos, sus dioses, demonios y palabras sagradas serán volubles y contingentes. 
La creación de sí no será la expresión de una potencia del ser, sino los desarrollos prácticos, contingentes y carentes de coherencia de un individuo que, huérfano de fundamento y carente de un vocabulario último, busca la maximización estética de sus deseos cambiantes, la realización de sus diferentes ansias determinadas por cada situación, por cada práctica. Un individuo sin interioridad que cuando, en la más absoluta de sus soledades, vuelva sus ojos sobre sí no encontrará nada más que vacío y deseos sin coherencia última. Un individuo vacío poblado por deseos ajenos, fascinado por el parpadeo cambiante y siempre novedoso de las luces de la ciudad irónica.

La cultura que Rorty defiende como deseable subvierte las relaciones sobre las cuales la filosofía tradicional fundaba su tarea. La ausencia de solidez teórica, la instauración de la antiepistemología, la sustitución de la verdad por la justificación, la división entre lo público y lo privado, la concepción retórica y persuasiva del lenguaje, la imposibilidad de trazar una ontología del presente, la ausencia de identidades, la contingencia del yo y de la comunidad, todo ello nos conduce a un escenario en el cual apelar a la fragmentación o las diferencias obliga, cuanto menos, definir convenientemente los términos que se pretenden oponer a un presente contingente, cambiante, injustificado, líquido. Y es aquí, en esta liquidez, donde el intelectual rortyano arraiga con toda su capacidad irónica. Es el intelectual que se adapta perfectamente a los cambios porque ha renunciado a la coherencia, el intelectual que asume la contingencia como parte de su propio ser y se pliega a las necesidades del poder a través de la propuesta de reformas, el fomento de la solidaridad y la creación privada, en donde cumple los sueños a través de sucesivas redescripciones. Podría decirse - y la presentación de Rorty de un intelectual semejante lo insinúaque estamos hablando de una suerte de anti-intelectual, un intelectual que acaba con las funciones clásicas de la filosofía, un intelectual definido como desertor. Y es que la misma cultura postfilosófica es una cultura en la cual la deserción es la consecuencia lógica y deseada del fomento de la contingencia. Con todo ello, si el intelectual clásico puede comprenderse como el intelectual de la cultura filosófica clásica contemporánea, y el intelectual post-nietzscheano puede leerse como el intelectual que se sitúa a la contra de dicha cultura - en tanto sospecha de la misma y lucha contra ella subvirtiendo sus fundamentos -, si ambos intelectuales pueden leerse como dos polos de una cultura llamada filosófica, el intelectual rortyano se nos aparece en una suerte de más allá, como un habitante de las ruinas que hace del territorio desértico y yermo de fundamentos el lugar perfecto para construir una ciudad irónica en la cual se satisfagan los deseos privados y cambiantes, donde el sentimentalismo justifique las verdades - o post-verdades- y, con los límites de la no crueldad, la solidaridad se convierta en la amalgama de los lazos colectivos. De este modo, la cuestión que aflora en los estertores de la modernidad y que nos compete porque apunta al corazón de nuestra actualidad, es la de en qué medida esa construcción de nosotros mismos, ese movimiento de autocreación basado en el creciente sentimentalismo, contiene elementos de liberación o se trata de una estrategia de asunción vital de las premisas neoliberales. 
Referencias

CALDER, G. Rorty. Madrid: Alianza, 2005.

CRITCHLEY, S. “Deconstrucción y pragmatismo: ¿Es Derrida un ironista privado o un liberal público?," en Ch.Mouffé (ed.), Deconstrucción y pragmatismo. Buenos Aires: Paidós, 2002.

DEWEY, J. La búsqueda de la certeza. México: FCE, 1952.

LIPOVETSKY, G. El crepúsculo del deber. La ética indolora de los nuevos tiempos democráticos. Barcelona: Anagrama, 1994.

RORTY, R. La filosofía y el espejo de la naturaleza. Madrid: Cátedra, 1983.

RORTY, R. Objetivismo, relativismo y verdad. Barcelona: Paidós, 1992.

RORTY, R. "Réponse à J.Bouveresse” en J.P.Cometti (ed.) Lire Rorty. Paris: Éclat, $1992 b$.

RORTY, R. Contingencia, Ironía y Solidaridad. Barcelona: Paidós, 1994.

Autor(a) para correspondência / Corresponding author: Rosa Martínez González. r.martinez@unizar.es 